\title{
COMPOSIÇÃO QUÍMICA E ATIVIDADE ANTIOXIDANTE DE INFLORESCÊNCIAS DE Lippia alnifolia Mart. \& Schauer
}

\author{
Horácio Freitas Bomfim¹; $^{1}$ Angélica Maria Lucchese ${ }^{2}$; Maira Meira de Freitas ${ }^{3}$ e \\ Amanda Ferreira Santana ${ }^{4}$ \\ 1. Bolsista PIBIC/FAPESB, Graduando em Farmácia, Universidade Estadual de Feira de Santana, e-mail: \\ hfreitasb@gmail.com \\ 2. Orientadora, Departamento de Exatas, Universidade Estadual de Feira de Santana, e-mail: \\ angelica.lucchese@gmail.com \\ 3. Participante do projeto, Departamento de Saúde, Universidade Estadual de Feira de Santana, e-mail: \\ mairafreitas_s2@hotmail.com \\ 4. Participante do projeto, Doutoranda em Recursos Genéticos Vegetais, Universidade Estadual de Feira de \\ Santana, e-mail: afs.27@ hotmail.com
}

PALAVRAS-CHAVE: Antioxidante; Frações; Lippia alnifolia;

\section{INTRODUÇÃO}

Lippia alnifolia Mart. \& Schauer, conhecida também como pedrécio, alecrim de vaqueiro, alecrim do mato, tem uso popular no tratamento de feridas ou queimaduras de pele. Também é empregado na forma de tintura para uso tópico, com a mesma finalidade, ou como gargarejo e bochecho nas infecções de garganta e da boca, ou em lavagens vaginais contra infecções. Essa mesma tintura, usada na forma de compressas locais, é muito eficiente no tratamento de acne, sarna infectada, panos brancos, impingem, caspas e mau cheiro dos pés, axilas e virilhas (Agra et al., 2008).

Em estudos da atividade antioxidante já realizados pelo nosso grupo de pesquisa com os extratos metanólicos brutos de inflorescência de Lippia alnifolia, utilizando o método de sequestro de radicais livres DPPH, a espécie demonstrou um excelente potencial antioxidante, com $\mathrm{CE}_{50}$ de $23,82 \mu \mathrm{g} / \mathrm{mL}$ (resultados não publicados). Quando comparado com outra espécie do mesmo gênero, como é o exemplo de Lippia graveolens com CE50 entre 152 a $207 \mu \mathrm{g} / \mathrm{mL}$ (Martínez-Rocha, et al., 2008), observa-se o quanto foram expressivos os resultados encontrados, demostrando a importância da continuidade dos estudos com a espécie Lippia alnifolia. Deste modo a realização de novos testes utilizando as frações hidrometanólica e clorofórmica do extrato de inflorescência, se faz necessário para a seleção da fração mais ativa para posterior identificação e isolamento dos metabolitos ativos.

\section{MATERIAL E MÉTODOS}

O extrato metanólico da inflorescência de Lippia alnifolia foi fracionado por partição líquido-líquido para obtenção das frações, no qual $18 \mathrm{~g}$ do extrato metanólico bruto foi ressuspenso em metanol:água $(7: 3 \mathrm{v} / \mathrm{v})$ e extraído com clorofórmio para obtenção das frações clorofórmica e hidrometanólica, visando uma semi-purificação das substâncias através de suas polaridades. A fração clorofórmica foi concentrada em evaporador rotatório e colocada para secar em capela de exaustão, enquanto a fração hidrometanólica teve o metanol retirado no evaporador rotatório e a solução final foi liofilizada.

A identificação da presença de antioxidantes e de compostos fenólicos foi realizada através de cromatografia em camada delgada, utilizando-se cromatoplacas de sílica com indicador de fluorescência, que foram eluídas, secas e visualizadas em luz UV-254 nm. Posteriormente, foram reveladas com o revelador NP/polietilenoglicol (NP/PEG), que detecta a presença de ácidos fenólicos e flavonoides; e solução de DPPH que indica a presença de substâncias com atividade antioxidante. As frações clorofórmica e hidrometanólica foram analisados empregando-se dois sistemas 
diferentes cloroformio/metanol (9,5:0,5 v/v) e acetato de etila/metanol/água (7:1,5:1,5 $\mathrm{v} / \mathrm{v} / \mathrm{v})$.

O teor de fenólicos foi determinado por espectrometria no UV-Vis $(750 \mathrm{~nm})$, pelo método de Folin-Ciocalteau, utilizando ácido gálico (AG) como padrão(Peres, 2009). A determinação de flavonoides foi por reação com $\mathrm{AlCl}_{3}$ em espectrometria no UV-Vis (425 nm), utilizando quercetina (Q) como padrão (Banov, 2006).

A atividade antioxidante foi determinada através do método de sequestro do radical livre 1,1-difenil-2-picrilhidrazila (DPPH) (Sousa, et al.,2007). As soluções das frações clorofórmica foram preparadas em concentrações $50 \mu \mathrm{g} / \mathrm{mL} ; 100 \mu \mathrm{g} / \mathrm{mL} ; 150$ $\mu \mathrm{g} / \mathrm{mL} ; 200 \mu \mathrm{g} / \mathrm{mL} ; 250 \mu \mathrm{g} / \mathrm{mL}$; e fração hidrometanólica com concentrações de 5 $\mu \mathrm{g} / \mathrm{mL} ; 10 \mu \mathrm{g} / \mathrm{mL} ; 15 \mu \mathrm{g} / \mathrm{mL} ; 20 \mu \mathrm{g} / \mathrm{mL} ; 25 \mu \mathrm{g} / \mathrm{mL} ; 30 \mu \mathrm{g} / \mathrm{mL}, 35 \mu \mathrm{g} / \mathrm{mL}$ e $40 \mu \mathrm{g} / \mathrm{mL}$. . $\mathrm{A}$ atividade antioxidante foi expressa pelo $\mathrm{CE}_{50}$ (quantidade necessária para sequestrar $50 \%$ do radical livre). Ácido ascórbico e trolox foram utilizados como controles positivos. Todos os ensaios foram realizados em triplicata.

\section{RESULTADOS E/OU DISCUSSÃO}

As frações clorofórmica e hidrometanólica oriundas da partição do extrato de inflorescências, após secas, foram devidamente pesadas e os dados de rendimentos estão apresentados na Tabela 1, observando-se que a fração hidrometanólica obteve o maior rendimento.

Tabela 1: Rendimento das frações clorofórmica e hidrometanólica provenientes do extrato bruto de inflorescências de Lippia alnifolia.

\begin{tabular}{c|c}
\hline Fração & Rendimento (\%) \\
\hline Clorofórmica & 21,83 \\
\hline Hidrometanólica & 71,44 \\
\hline
\end{tabular}

As amostras foram aplicadas em igual volume nas placas cromatográficas de sílica gel e após a pulverização dos reveladores NP/PEG foi detectado tanto na fração hidrometanólica (figura $1 \mathrm{~A}$ ) como na clorofórmica (figura $1 \mathrm{~B}$ ) a presença de ácidos fenólicos e flavonoides.
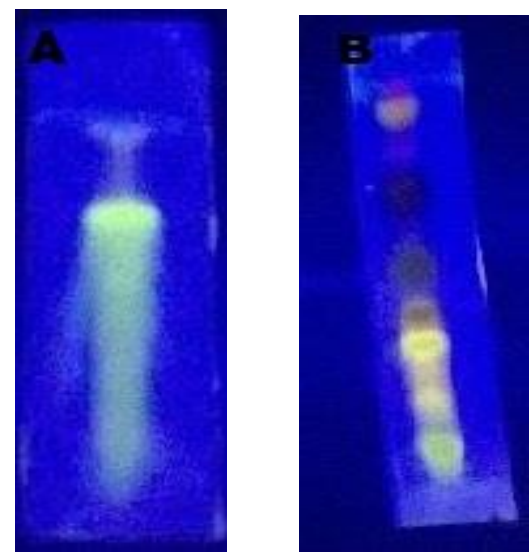

Figura 1. Cromatografia em camada delgada utilizando NP/PEG como revelador. Em luz UV $254 \mathrm{~nm}$ : (A) Fração Hidrometanólica (B) Fração Clorofórmica

Também foi possível identificar a presença de substâncias com atividade antioxidante em ambas as frações, através da revelação com DPPH (Figura 2). Nesta técnica de bioautografia a formação de halos brancos ou amarelados indica a presença de compostos com ação antioxidante pelo sequestro do radical DPPH, de coloração violeta. 

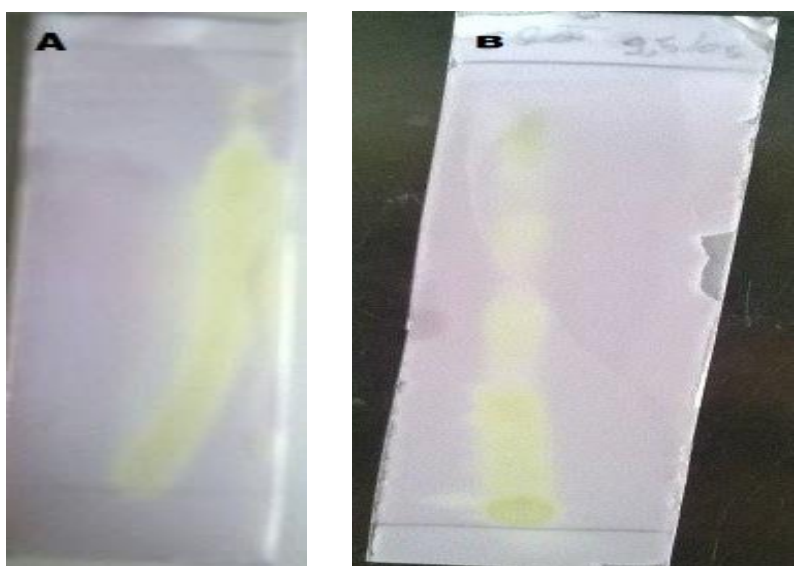

Figura 2. Cromatografia em camada delgada utilizando DPPH como revelador: (A) Fração Hidrometanólica (B) Fração Clorofórmica

Os dados do teor de fenólicos e flavonoides totais das frações clorofórmica e hidrometanólica estão reunidos na tabela 2 , onde é apresentada a média da triplicata, bem como o desvio padrão.

Tabela 2. Teor de fenólicos e flavonoides totais das frações clorofórmica e hidrometanólica provenientes do extrato metanólico das inflorescências de Lippia alnifolia.

\begin{tabular}{c|c|c}
\hline Frações & $\begin{array}{c}\text { Fenólicos } \\
\text { Média }( \pm \mathbf{D P}) \mathbf{m g} \\
\mathbf{E A G / g}\end{array}$ & $\begin{array}{c}\text { Flavonoides } \\
\text { Média }( \pm \mathbf{D P}) \\
\mathbf{m g ~ E Q / g}\end{array}$ \\
\hline Clorofórmica & $88,15 \pm 1,31$ & $29,53 \pm 1,00$ \\
\hline Hidrometanólica & $245,43 \pm 5,03$ & $5,93 \pm 0,26$ \\
\hline
\end{tabular}

O teor de compostos fenólicos e flavonoides totais observados na tabela 2 indicam o potencial da inflorescência de Lippia alnifolia como fonte de compostos antioxidantes. Não houve correlação entre os valores de fenólicos e de flavonoides para as frações analisadas, pois a fração hidrometanólica apresentou o maior teor de fenólicos e a clorofórmica o maior teor flavonoides. Esta variação pode ser decorrente de uma interferência do método adotado na quantificação de flavonoides. No mesmo, o cloreto de alumínio é um agente complexante, que aumenta o comprimento de onda da absorção máxima, intensificando-a, evitando assim a interferência de outros compostos fenólicos na leitura. Mas os complexos de flavonóis com alumínio absorvem próximos a faixa de $425 \mathrm{~nm}$, enquanto as flavonas, por exemplo, absorvem em comprimentos de onda inferiores, podendo dessa forma ter ocorrido uma subestimação do valor de flavonoides na mistura, em função de diferentes classes destes metabólitos (Mabry et al. 1970).

Os dados da atividade antioxidante, avaliada pelo sequestro do radical livre DPPH, estão representados pelo $\mathrm{CE}_{50}$ obtido pela média das triplicatas das frações clorofórmica e hidrometanólica do extrato de inflorescência calculados por regressão linear. A média dos valores de $\mathrm{CE}_{50}$ dos extratos e dos controles positivos (ácido ascórbico e Trolox) estão apresentados na Tabela 3.

Tabela 03. Valores médios de $\mathrm{CE}_{50}$ da fração clorofórmica e hidrometanólica de Lippia alnifolia, do ácido ascórbico e Trolox em $\mu \mathrm{g} / \mathrm{mL}$

\begin{tabular}{l|c|c|c|c}
\hline & Fração & Fração clorofórmica & & \\
Lippia/ & hidrometanólica & Média $( \pm \mathrm{DP})$ & Trolox & Ácido \\
\hline
\end{tabular}




\begin{tabular}{l|c|c|c|c}
\hline Padrão & $\begin{array}{c}\text { Média }( \pm \mathrm{DP}) \\
\mu \mathrm{g} / \mathrm{mL}\end{array}$ & $\mu \mathrm{g} / \mathrm{mL}$ & & ascórbico \\
\hline CE50 & $22,74 \pm 1,58$ & $154,27 \pm 30,84$ & $12,05 \pm 0,67$ & $10,11 \pm 0,66$ \\
\hline
\end{tabular}

Na atividade antioxidante, utilizando-se o método de DPPH, quanto menor for o $\mathrm{CE}_{50}$ de uma amostra, maior é a sua atividade antioxidante, já que a mesma necessita de concentrações menores para um maior consumo de DPPH. Dentre as frações a fração hidrometanólica foi a que apresentou o menor $\mathrm{CE}_{50}$ (tabela 3), onde o resultado foi muito superior ao encontrado para a fração clorofórmica. Este resultado era esperado, pois a fração hidrometanólica apresentou uma quantidade muito superior de fenólicos em relação a fração clorofórmica (Tabela 2), sendo os fenólicos descritos na literatura como um dos principais metabolitos secundários responsáveis por apresentar atividade antioxidante.

\section{CONSIDERAÇÕES FINAIS}

Ambas as frações apresentam potencial na busca por novas substâncias com atividade antioxidante, com destaque para a fração hidrometanólica que obteve os melhores resultados. Assim, estudos posteriores deverão ser realizados visando o isolamento e a identificação dos compostos presentes nas frações.

\section{REFERENCIAS}

AGRA, M. F., et al. Survey of medicinal plants used in the region Northeast of Brazil. Rev Bras Farmacogn. 18: 472-508, 2008

BANOV, D. et al. Caracterização do extrato seco de Ginkgo biloba L. em formulação de uso tópico. Acta Form. Bonaerense 25(2) : 219-24.2006.

MABRY, T.J. et. al. The systematic identification of flavonoids. Springer: Berlin, 1970.

MARTÍNEZ-ROCHA, A. et al. Antioxidant and Antimutagenic Activities of Mexican Oregano (Lippia graveolens Kunth). plant foods for human nutrition. 2008.

PERES, M. T. L. P et al. Estudos químicos e biológicos de Microgramma vacciniifolia (Lansd. \& Fisch.) Copel (Polypodiaceae). Química Nova, v. 32, n.4, p. 897-901. 2009.

SOUSA, C. M. M. et al. Fenóis totais e atividade antioxidante de cinco plantas medicinais. Química Nova, v. 30, n.2. p. 351-355, 2007. 